\title{
Cytogenetical Studies in the Inbred Lines of Radish (Raphanus sativus L. var. radicols Pers.) and their Hybrids. I. Chiasma Frequency
}

\author{
Narsinha Dayal \\ Department of Botany, Ranchi University, Ranchi, India
}

Received May 1, 1975

Studies of meiosis in the inbred lines of allogamous population and their hybrids serve as one of the most important tools for understanding the genetics of chromosome behaviour. Character of combination and recombination, reduction of chromosome number and the degree of fertility depend on chromosome behaviour during meiosis and particularly, on the success of chromosome pairing. The biological significance of meiosis is contained in the ability of chromosomes to pair; therefore from their aberrant behaviour the nature of system regulating chromosome pairing can crudely be inferred. The study of aberrant meiosis and specially genetically determined deviations from normal chromosome behaviour, therefore, is quite important for understanding the genetic regulation of meiosis.

In heterzygous allogamous populations chromosome pairing namely the chiasma frequency displays a definite limit in variation and may be considered as an adaptive character. This property of population is, probably, maintained by heterozygosity in so far as forced inbreeding of a normally allogamous population leads to the appearance of unbalanced genetic system in them; the plants of inbred lines show a general decline in fertility and vigour (Shull 1911, 1948, East and Jones 1919, Jones 1939, Müntzing 1945, Narbut 1961, 1964).

Existence of genes controlling the chromosome behaviour was suggested long ago by Darlington (Darlington 1932). It has been found to be under genotypic control. Any deviation from normal chromosome behaviour is exposed to natural selection which may lead to important adaptive changes in the mechanism of its inheritance.

The genetic alterations of chiasma frequency has been an object of study for quite some time. However, the most informative studies have been concerned with the unbalanced genotypes arising out of forced inbreeding of allogamous populations. Lamm (1936) was the first to report a significant lowering of chiasma frequency in the inbred lines of rye in comparison to the original population. The work of Lamm has been confirmed and developed by Müntzing and Akidk (1948) and Rees et al. (1955a,b, 1961, Rees and Thompson 1956). Lowering of chiasma frequency has also been shown for inbred lines of other plants (Zecevic 1960, 1961, Myers and Hill 1943).

The present report deals with the study of chiasma frequency in three inbred lines of radish, Raphanus sativus $L$. var. radicola Pers., and their $F_{1}$ hybrids in comparison to their original population. 


\section{Material and method}

\section{Material}

Three inbred lines of radish, namely LS-337/25( $\left.\mathrm{I}_{11}\right)$ LS-337/24( $\left.\mathrm{I}_{11}\right)$ and LS-43/ $51\left(\mathrm{I}_{16}\right)$, derived from the varietal population "Saxa" and their reciprocal $F_{1}$ hybrids have been used in the present study. These lines were selected from the genetic collection of Dr. S. I. Narbut of the Chair of Genetics and Plant breeding, Leningrad State University, Leningrad and are genetically well studied (Narbut, 1966, 1967, Dayal 1973). The first two lines were derived from a single plant of $I_{1}$ and are, therefore, sisterly. The line LS-337/24 is a chlorophyll mutant of the type "viridis" and is characterized by the formation of genetic tumours on the root. Its sister line LS-337/25 has normal green leaves with no tumours on the root. Both lines show inbreeding depression in many morpho-physiological characters. The third line, LS-43/51 has a different origin and its plants do not differ much from those of population in many characters. All these lines are highly homozygous.

\section{Method}

For cytological examinations flower buds from four plants of each forms were fixed and mordanted in acetoalcohol (1:3) containing a few drops of $\mathrm{FeCl}_{3}$. The fixation was made between 10 and 11 a.m. in the first half of June 1971. After storing at low temperature in $70 \%$ alcohol, the anthers were stained \& squashed in $1.5 \%$ acetocarmine. The scoring was made at diakinesis in 20 pollen mother cells in each plant. For interpretation of bivalents only well-squashed cells were studied (Fig. 1).

\section{Results}

\section{Population and inbred lines}

As it follows from the present investigation, the most striking characteristic in diakinesis of inbred lines of radish in comparison to its original population is the significant reduction of chiasma frequency in the former (Table 1, Fig. 2). Besides the plants belonging to the inbred lines showed more variation, though not

Table 1. Mean chiasma frequency in diakinesis in the inbred lines of radish, their $F_{1}$ hybrids and the population

\begin{tabular}{|c|c|c|c|c|c|c|c|}
\hline \multirow{2}{*}{ Materials } & \multicolumn{4}{|c|}{$\begin{array}{l}\text { Number of X'ta per bivalent } \\
\text { in plants }\end{array}$} & \multirow{2}{*}{$\begin{array}{l}\text { Mean chiasma } \\
\text { frequency } \\
\text { Mean } \pm \text { S.E. }\end{array}$} & \multirow{2}{*}{$\sigma$} & \multirow{2}{*}{$\begin{array}{l}T d \text {. to } \\
\text { popula- } \\
\text { tion }\end{array}$} \\
\hline & 1 & 2 & 3 & 4 & & & \\
\hline Population "Saxa" & 1.933 & 2.027 & 1.894 & 1.916 & $1.94 \pm 0.029$ & 0.058 & 0.0 \\
\hline $\mathrm{LS}-337 / 25$ & 1.716 & 1.633 & 1.533 & 1.777 & 1.66 & 0.0 & 5.6 \\
\hline LS $-337 / 24$ & 1.556 & 1.505 & 1.672 & 1.520 & $1.57 \pm 0.021$ & 0.043 & 10.5 \\
\hline $\mathrm{LS}-43 / 51$ & 1.850 & 1.855 & 1.855 & 1.761 & $1.83 \pm 0.021$ & 0.043 & 3.1 \\
\hline LS-337/24 × LS-337/25 & 1.861 & 1.866 & 1.866 & 1.844 & $1.86 \pm 0.005$ & 0.010 & 2.8 \\
\hline LS-337/25 $\times$ LS $-337 / 24$ & 1.872 & 1.844 & .1877 & 1.827 & $1.86 \pm 0.011$ & 0.023 & 2.9 \\
\hline LS-43/51 $\times$ LS-337/24 & 1.833 & 1.822 & 1.838 & 1.844 & $1.83 \pm 0.009$ & 0.019 & 3.6 \\
\hline LS $-43 / 51 \times$ LS $-337 / 25$ & 1.850 & 1.838 & 1.850 & 1.844 & $1.85 \pm 0.003$ & 0.006 & 3.2 \\
\hline LS-337/24 $\times$ LS $-43 / 51$ & 1.877 & 1.855 & 1.872 & - & $1.87 \pm 0.005$ & 0.011 & 2.5 \\
\hline
\end{tabular}

Note: Value of $T d \geq 3$ is statistically significant. 
significant, within the family in chiasma frequency than those of population. The mean chiasma frequency in the line LS-337/25 is equal to 1.66 per bivalent whereas for the line LS-337/24 this value is 1.57 only. A higher chiasma frequency -1.83 is characteristic for the line LS-43/51, occupying an intermediate position between

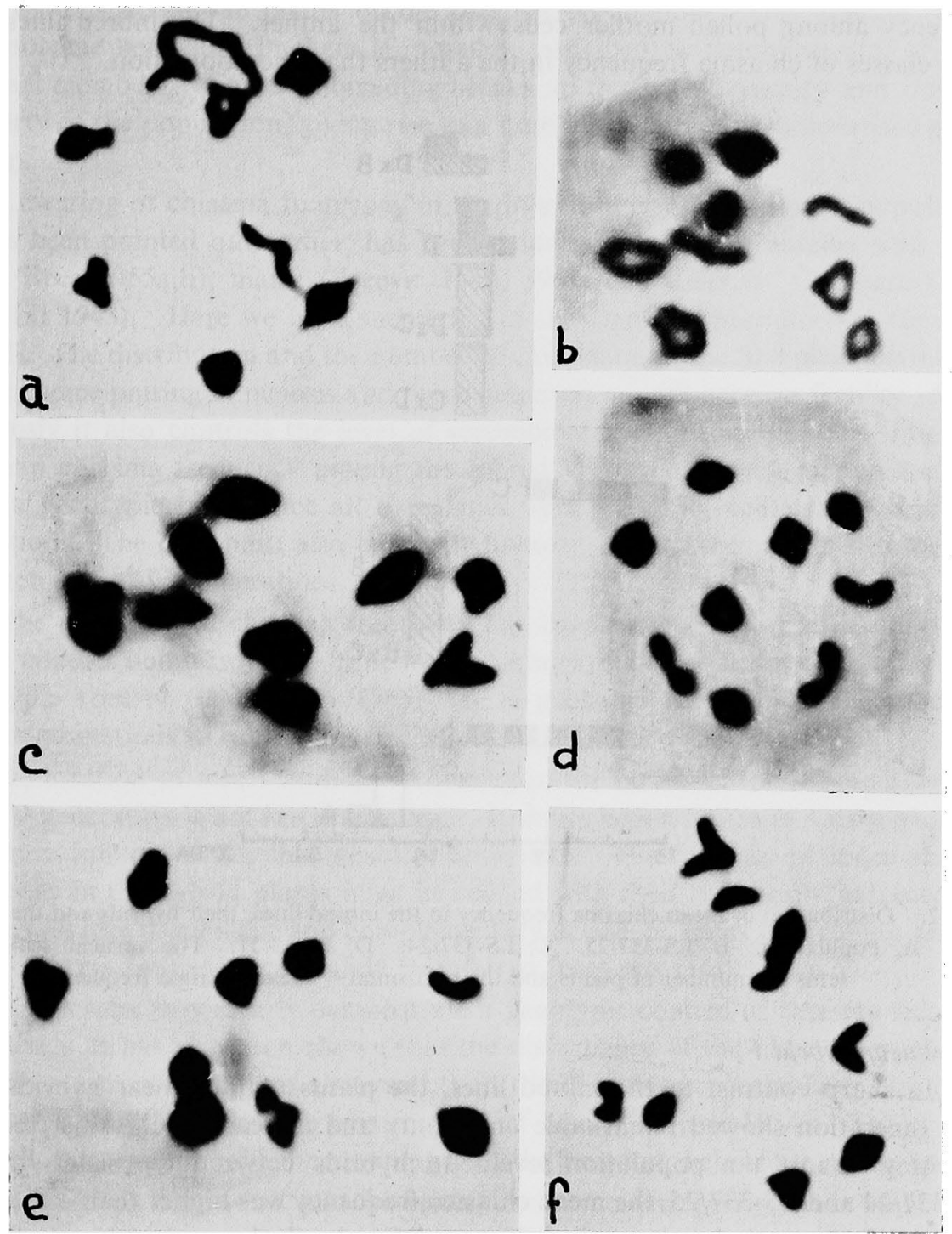

Fig. 1. Diakinesis in the inbred lines, their hybrids and the population. a-b, $F_{1}$ hybrids of LS$337 / 24$ and LS-337/25. c, population; $d-f$, inbred lines. Increase in the number of rod bivalents and decrease in chiasmata number in the inbred lines may be noted.

sister lines and the population. It is worthwhile to mention that this line does not show inbreeding depression even in the 15 th generation of inbreeding and is in no way inferior to the original population in fertility and vigor. All these lines differ significantly among themselves as well as from the population in mean chiasma 
frequency.

The second important characteristic of meiosis in the inbred lines is the increase of rod bivalents in them. The number of such bivalents is higher in the lines, especially in LS-337/24 and LS-337/25 than the population. Another feature of interest of meiosis in the inbred lines of radish is greater variation in chiasma frequency among pollen mother cells within the anther. The inbred lines show more classes of chiasma frequency in the anthers than the population.
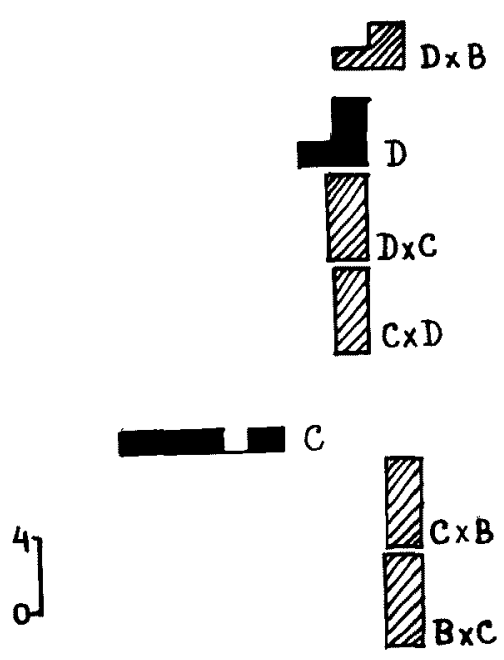

min

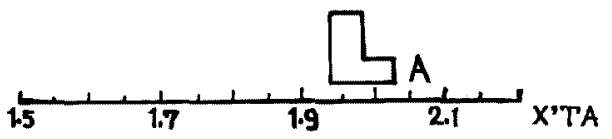

Fig. 2. Distribution of mean chiasma frequency in the inbred lines, their hybrids and the population. A, Population. B, LS-337/25. C, LS-337/24. D, LS-43/51. The vertical scale represents the number of plants and the horizontal - mean chiasma frequency.

\section{Interlinear hybrid $\boldsymbol{F}_{4}$}

In sharp contrast to the inbred lines, the plants of interlinear hybrids in the first generation showed remarkable uniformity and increase of chiasma frequency, touching almost the population level. In hybrids between the sister lines, i.e. LS-337/24 and LS-337/25, the mean chiasma frequency was higher than either of the parental forms and almost touched the population level whereas in other three hybrid forms, one of the parents namely LS-43/51 dominated (Table 1, Fig. 2). An increase in chiasma frequency is characteristic for all the hybrid forms. Besides the number of rod bivalents per nucleus and cell variance in chiasma frequency within the anther is less than the lines. In other words, a normal chromosome behaviour is restored in the $F_{1}$ hybrids between the inbred lines. 


\section{Discussion}

Radish is a typical cross-pollinating plant whose reproductive biology has been shaped in the long course of evolution. During this an optimum level of mean chiasma frequency and normal segregation of chromosomes at anaphase-I have been established in the plants of the original population. This definite type of chromosome behaviour in them is, possibly, provided by heterozygosity of its individual members. Forced inbreeding breaks up this heterozygosity and buffering property of the population, giving rise to a number of lines with unbalanced genetic system.

Lowering of chiasma frequency in the inbred lines of allogamous populations, as has been pointed out earlier, has been described for rye (Müntzing and Akdik 1948, Rees 1955a,b), maize (Zecevic 1960, 1961) and Dactylis glomerata (Myers and Hill 1943). Here we have succeeded in showing this phenomenon for radish as well. The distribution and the number of chiasmata, in the first place characterize chromosome pairing in meiosis and therefore, exert an influence on fertility. Simultaneously it also controls the level of recombinational variation. The differences in mean chiasma frequency among the inbred lines of the same population must have a genotypic basis since all the plants were grown in identical environmental condition. The lines must also be highly homozygous for they are inbred for more than ten successive generations.

The reduction in chiasma frequency has been ascribed to result from a 'shift in the contact points' and the 'time limit' during synapsis, both of which are under genotypic control (Darlington 1965). It is probable that different homozygous gene combinations in inbred lines affect these processes differently.

Restoration of mean chiasma frequency in the plants of interlinear hybrids in the first generation is not less interesting. It shows how a return to a natural mating condition influences the chromosome behaviour. The increase of mean chiasma frequency in the hybrid plants must be related with their genetically balanced condition. Besides dominance and complementary action of genes controlling an optimum chiasma frequency can safely be inferred from our results (Fig. 2).

Our results very clearly demonstrate a genotypic control of chiasma frequency in radish. It has also been shown that the disturbance of the natural reproductive system in a species leads to abnormality in the chromosome behaviour due to loss of genetic balance or 'genetic homeostasis' of Lerner (Lerner 1954). The chromosome pairing is definitely concomitant with the breeding behaviour of the species.

'Inbreeding depression' and 'heterosis' in chromosome pairing have been shown.

The nature of genetic control and mechanism for regulation of chromosome behaviour are yet to be solved. Discussing the possible types of control for meiotic chromosome behaviour an intricate interaction of nonallelic genes for its realization has been proposed (Riley and Law 1965, Riley 1966). A polygenic control of chisma frequency has also been established in rye (Müntzing and Akdik 1948, Rees 1961) and in maize (Zecevic 1960, 1961). Our results too point to, if not demonstrate, a polygenic regulation of chiasma frequency in radish, but only a further investigation may confirm this. 


\section{Summary}

Mean chiasma frequency at diakinesis has been studied in three intered lines of radish, namely LS-337/24, LS-337/25 and LS-43/51, their $F_{1}$ hybrids and the population. It has been demonstrated that the lines significantly differ among themselves and from the original population in this character. All the lines show a marked reduction in mean chiasma frequency in comparison to the population whereas the interlinear hybrids $F_{1}$ are characterized by increase of this mean which touches almost the population level. From our results it is quite obvious that the breakdown and restoration of chromosome pairing are concomitant with the mating system of the species. A genotypic control of mean chiasma frequency has been proposed in radish.

\section{Acknowledgements}

It is pleasure to thank Professor T. S. Fadeyeva, D.Sc. and Dr. S. I. Narbut of the Chair of Genetics and Selection, Leningrad State University, Leningrad for valuable suggestions and criticism during the work.

\section{References}

Darlington, C. D. 1932. The control of chromosome by the genotype and its bearing on some evolutionary problems. Am. Naturalist 66: 25-51.

- 1965. Recent Advances in Cytology, 1937-1964. P. 1, London, Churchill, 1965.

Dayal, N. 1973. Ph. D. Thesis, Leningrad State University, Leningrad.

East, E. M. and Jones, D. F. 1919. Inbreeding and Outbreeding, their Genetic and Sociological Signification. Philadelphia, London, 1919.

Jones, D. F. 1939. Continued inbreeding in maize. Genetics 24: 462-473.

Lamm, R. 1936. Cytological studies on rye. Hereditas 31: 217-240.

Lerner, I. M. 1954. Genetic Homoestasis. New York, 1954.

Müntzing, A. 1945. On the causes of inbreeding depression. Archiv. d. Julius Klaus Stiftung Erganzungsband zu, Bd. 20: 153-163.

- and Akdik, S. 1948. Cytological disturbances in the first generation of rye. Hereditas 334: 485-509.

Myers, W. M. and Hill, H. D. 1943. Increasing meiotic irregularities accompanying inbreeding in Dactylis glomerata. Genetics 28 : 249-254.

Narbut, S. 1. 1961. Ob izmenchivosti plodovitisti u redisa pri intsukhte (About variation in fertility in radish due to inbreeding). Issleydovaniya po Genetike, No. 1: 139-146 (In Russian; Summary in English).

- 1964. Razlozheniya sortovikh populyatsii redisa putyom inbridinga (Disintergration of varietal populations of radish by means of inbreeding). Ibid No. 2: 90-99 (In Russian; summary in English).

- 1966. Geneticheskaya kollektsiya inbrednikh liniya redisa (Genetic collection of inbred lines of radish). Genetika, No. 5: 89-100 (In Russian, summary in English).

- 1967. Geneticheskaya opulkhal u redisa, poluchenaya pri inbridinge (Genetic tumour in radish due to inbreeding). Vestnik L.G.U., No. 15, Biol., Bip. 3: 144-149 (In Russian, summary in English).

Rees, H. 1955a. Genotypic control of chromosome behaviour in rye I. Inbred lines. Heredity 9: 93-116.

- 1955b. Heterosis in chromosome behaviour. Proc. Roy. Soc. B. 144: 150-159. 
Rees, H. 1961. Genotypic control of chromosome form and behaviour. Bot. Rev. 27: 288-318. - and Thompson, J. B. 1956. Genotypic control of chromosome behaviour in rye III. Chiasma frequency in heterozygotes and heterozygotes. Heredity 10: 409-421.

Riley, R. 1966. Genetics and the regulation of meiotic chromosome, behaviour. Sci. Progress 54: 193-207.

Riley, R. and Law, C. N. 1965 . Genetic variation in chromosome pairing. Adv. in Genet. 13: 57-114.

Shull, S. H. 1909. The genotypes of maize. Am. Naturalist 45: 234-252.

- 1948. What is 'heterosis'? Genetics 33: 439-446.

Zecevic, L. M. 1960. Cytogenetic studies of inbred lines of maize I. Chiasma frequency at diplotene. Zbor. radova Biol. Instt. 4: 1-32. (In Yugoslavian, summary in English and Russian).

- 1961. Ditto II. Chiasma frequency at diakinesis. Ibid. 5: 1-43. (In Yugoslavian, summary in English and Russian). 